\title{
El consumo de libros frente a las nuevas tecnologías de la información. Reflexiones a partir de los resultados de una encuesta de lectores
}

\author{
O consumo de livros frente às novas tecnologias da informação. \\ Reflexões a partir dos os resultados de uma pesquisa com leitores
}

The consumption of books facing the new information technologies. Thoughts on the results of a reader survey

\author{
Dr. Edwin Juno-Delgado ${ }^{1}$ \\ Elise Iwasinta
}

"De los diversos instrumentos del hombre, el más asombroso es, sin duda, el libro. Los demás son extensiones de su cuerpo. El microscopio, el telescopio, son extensiones de su vista; el teléfono, de la voz. Pero el libro es otra cosa: es una extensión de la memoria y de la imaginación".

Jorge Luis Borges ${ }^{3}$

Palabras clave:

Consumo de libros

Nuevas tecnologías

Tecnologia de la

información

Lectores

\section{Resumen:}

Nuestro trabajo busca responder a la siguiente pregunta: ¿Cómo la web puede influir en la su elección de la lectura de los usuarios literarios?

Este problema, obviamente, plantea una multitud de sub-preguntas. Vamos a estudiar las siguientes áreas:¿Cómo las opiniones de los demás, "boca a boca", pueden influir en la decisión del lector para comprar un libro? ¿Cómo la Web puede facilitar esta influencia, y de qué manera? ¿Cómo las editoriales pueden interactuar con este fenómeno?

Vamos a estudiar diversas teorías inicialmente propuestas sobre prescripción y comunidades en línea. En primer lugar, se analiza el aspecto social y subjetivo del libro como objeto, luego examinamos el lugar del libro en Internet, a través de los diferentes actores y soportes visibles, y el impacto de la conectividad en el consumo. Después, vamos a ver cómo los fans en Internet juegan un papel en la elección de la lectura, y los límites de esta influencia. Finalmente, presentamos los resultados de estudio cuantitativo y analizamos las tendencias que pueden identificarlos puntos clave que podrían ser de utilidad para los profesionales del libro. 
Resumo:

Nosso trabalho procura responder a seguinte pergunta: como a Web pode influenciar na escolha da leitura dos usuários literários?

Este problema, obviamente, levanta uma multiplicidade de subperguntas. Vamos estudar as seguintes áreas: como as opiniões dos outros, "boca a boca", podem influenciar na decisão do leitor para comprar um livro? Como a Web pode facilitar esta influência e de que maneira? Como as editoras podem interagir com este fenômeno?

Vamos estudar diversas teorias inicialmente propostas sobre prescrição e comunidades online. Em primeiro lugar, analisa-se o aspecto social e subjetivo do livro como objeto, em seguida examinamos o lugar do livro na Internet, através dos diferentes atores e suportes visíveis, e o impacto da conectividade sobre o consumo. Depois, vamos ver como os fãs na Internet desempenham um papel na escolha da leitura e os limites desta influência. Finalmente, apresentamos os resultados de um estudo quantitativo e analisamos as tendências que podem identificar os pontos-chave que poderiam ser úteis para os profissionais do livro.

\section{Palavras chave:}

Consumo de livros

Novas tecnologias

Tecnologia da informação

Leitores

\section{Keywords:}

Consumption of boks

New technologies

Information technology

Readers

\section{Abstract:}

Our work seeks to answer the following question: how can the Web influence the reading choices of the literary users?

This issue obviously raises a multitude of sub-questions. We will study the following areas: how can the opinions of others, "word of mouth", influence a reader's decision to buy a book? How can the Web facilitate this influence? How can the publishers interact with this phenomenon?

We will study several theories initially proposed about prescription and online communities. First, the social and subjective aspect of the book as an object is analyzed, then we examine the place of the book in the Internet, through the different visible actors and supports, and the impact of connectivity on the consumption. Afterwards, we will see how the fans in the Internet play a role in the reading choices and the limits of this influence. Finally, we present the results of a quantitative study and analyze the trends that may identify the key points which could be useful for the professionals of the book. 


\section{El consumo de libros frente a las nuevas tecnologías de la información. Reflexiones a partir de los resultados de una encuesta de lectores}

\section{Introducción}

La lectura de un libro literarioestá fuertemente relacionada con la subjetividad de cada uno de nosotros y con el momento en que se lee.Leemos un libro una sola vez, pues si volvemos a leer el mismo libro, no leemos lo mismo, pareciera que el texto fuese otro, la connotación de las palabras otra. Del mismo modo, cada lector construye su propia opinión sobre lo que lee.

Entonces cabe preguntarse ¿Cómo y para qué utilizar las opiniones de los lectores en la estrategia de promoción y de venta de un libro? Hoy en día los clubes de lectores, en los que podemos encontrar informaciones, consejos y encuestas, prosperan cada vez gracias a Internet, se han convertido en un "lugar" de encuentro entre los profesionales del libro y los lectores.

Este artículo tiene como objetivo entender cómo la Web puede influir en las opciones de lectura literaria y enseguida en la decisión de compra de libros literarios a través de blogs, redes sociales y comunidades de lectores en línea. Gracias a un estudio cuantitativo de 871 usuarios hemos podido establecer un perfil de este nuevo "consumidor de libros literarios". Esta investigación nosmuestra la influencia de los blogs literarios en el consumidor; pero, al tiempo, también revela las limitaciones de la prescripción en línea, y presenta propuestas concretas para los profesionales del libro para utilizar mejor estas nuevas herramientas.

Imaginemos a dos personas que están conversando sobre un libro. Para la primera persona"la última novela" del autor "X" es excelente, la mejor de todas las novelas escritas por este autor. La otra persona, en cambio, piensa que "la última novela" del autor " $X$ " no es tan buena como las anteriores novelas del mismo autor. ¿Quién tiene razón? Difícil de dar razón a uno más que al otro. El problema es que si el comprador duda al momento de su decisión de comprar de un libro como una lectura de verano, ¿Cuál de las dos opiniones va a escuchar?

Todos hemos experimentado este tipo de debate sobre una película, una exposición artística o un libro. Todo el mundo tiene su propia opinión, y a veces las opiniones pueden ser completamente contradictorias. Algunas personas adoran las novelas de Vargas Llosa, otras las odian, los lectores se encuentran en medio de este debate y a veces pierden el interés por el libro a causa de todas las opiniones contradictorias que recibe en el momento de la decisión de compra.

Además, a veces cambiamos de opinión sobre un autor. Nos gustó su primer trabajo, pero su cuartanovela nos ha decepcionado. Cambiar de opinión es normal, hay que recordar lo que decía Jane Austen en su célebre "Pride and Prejudice": "Los que nunca cambian de opinión deben, por supuesto, asegurarse de juzgar la primera vez, sin cometer errores".

El libro es un producto cultural, y como todo producto cultural está sujeto a la subjetividad de cada consumidor, de cada lector. A menudo buscamos consejo aquí y allí, en la prensa, con nuestros amigos, o incluso en la Internet para encontrar consejos antes de comprar un libro. Lo que ha cambiado hoy es que el valor literario de un libro se construye "en línea". Asistimos a una nueva forma de consumir literatura, el "consumo 2.0". Este nuevo fenómeno de "Lectura social" intriga cada vez más a los profesionales del libro, ya sean autores o editores. 
Las empresas de edición no pueden ignorar el impacto del fenómeno tecnológico y social que representan las redes sociales en el mundo del libro. Muchas de estas empresas comienzan a comprender este fenómeno y a adaptarse mediante la creación de una identidad real a partir de la cual invitan a los usuarios a participar activamente en la valorización de un libro literario. En efecto los consumidores de libros están cogiendo cada vez más importancia en las estrategias de marketing de la empresa, gracias a la libertad que tienen para expresar sus deseos y sus opiniones sobre la web como en la vida real.

Internet es un espacio de libertad, en el que todo el mundo habla y da su opinión. Esta nueva forma de crear opinión, una suerte de "boca a boca" no es un fenómeno nuevo, pero se necesita una nueva estrategia marketing que utilice las redes sociales activamente. Hace 20 años, lacrítica de una marca dentro del círculo familiar tenía poca importancia, hoy esto ha cambiado radicalmente pues un simple tweet puede poner en peligro unacarrera. De este modo, la opinión de los internautas que se difunde à través Internet es más importante que nunca. El sector cultural se ve especialmente afectado por este fenómeno de "boca-a- boca virtual", y el mundo editorial sufre las consecuencias aún más. A diferencia del cine o de la música, los libros sólo tienen publicidad tradicional rara vez y el "boca-a - boca" sigue siendo un factor importante en el proceso de decisión de compra. Este intercambio de opiniones sobre las lecturas es cada vez más importante en Internet, a través de comunidades en línea de lectores que a veces comprenden decenas de miles de miembros, gracias a cientos de blogs literarios, algunos de los cuales son cada vez más profesionales, y gracias a las páginas de cada autor o los websites de las casas edición que se multiplican en Facebook, Twitter y otros.
El objetivo de este artículo es estudiar estas prácticas y tratar de cuantificarlas. Las prácticas literarias varían enormemente de un país a otro, este artículo se centrará en el sector de la edición literaria en Francia, pero esperamos que las conclusiones de nuestro trabajo puedan servir como ejemplo para otros países, especialmente latinoamericanos, como Brasil. Un país que muy involucrado en la "lectura Social 2.0 " y en la web literaria.

La mayor parte de los usuarios que actúan intercambian opiniones a través de las redes sociales y comunidades en línea son los que los investigadores sociales Ilaman la "Generación Y", las personas que tienen entre 18-30 años, conocidos también como los "ultra - conectados" (LEVAIN ET AL., 2012). Nuestro trabajo se centra principalmente en este tipo de consumidor de literatura, pero esto no nos evita de hacer comparaciones con otros tipos de consumidores con el fin de lograr resultados más fieles a la realidad. Las principales áreas de estudio serán las redes sociales, los sitios web generales y especializados, comunidades de lectores y blogs literarios.

\section{Capítulo I: El consumo de libros litera- rios y la prescripción}

\section{A. El libro, una cuestión de la subjeti- vidad}

Volvamos al ejemplo de nuestra introducción. Las dos personas que hablan sobre un libro no están de acuerdo. A la primera, le encantó la última novela de Vargas Llosa, a la otra no le gusta nada. ¿Cuál de estas dos opiniones será la que se tomará en cuenta en el momento de la decisión de compra? Si no se está seguro, ahora podemos leer artículos de un periodista literario en una revista especializada o un periódico, escuchar la crítica en la televisión o la radio, ver si la novela o el es- 
critor han ganado un premio literario; pero si las opiniones son contradictorias, la decisión de compra puede llegar a ser muy dificil. De hecho, a menudo nosotros mismos construimos nuestra propia opinión, mediante la lectura. Virginia Woolf evoca acertadamente en su Arte de la Novela en 1962: "El único consejo que una persona puede dar a otra sobre la lecturaes no pedir ningúnconsejo, seguir sus propios instintos, usar su propia razón,para llegar a sus propias conclusiones".

El libro, al igual que otros bienes culturales, está especialmente sujeto a la subjetividad de los consumidores. Para Michel Gensollen, los bienes culturales son de hecho "mercancías que llevan la información y / o que necesitan información para ser seleccionados y consumidos" (GENSOLLEN, 2004, p. 6). La opinión del lector es entonces particularmente importante en el proceso de toma de decisión y el consumo.

Gensollen (2004) también afirma que la evaluación del libro está sujeta a la discreción de cada consumidor, es un bien de calidad horizontal. De este modo, se diferencia de los otros bienes llamados bienes de calidad vertical, en los que la evaluación es objeto de una clasificación objetiva reconocida por todos. Pero esta clasificación objetiva no existe para el libro. Incluso sería difícil de alcanzar. ¿Qué datos considerados en este ranking? El estilo del autor, el tema del libro, el número de páginas? Aún con estos datos objetivos, es imposible estar cien por ciento seguro del éxito comercial de un libro, porque probablementeel contenido no va a complacer a todos los lectores. De hecho, los libros galardonas con premiosliterarios no son necesariamente apreciados por todos los lectores, y que a menudo escuchamos de gente decepcionada por el último libro que ha ganado el "Premio Goncourt". Así, no se puede hablar de una forma objetiva de un buen libro o un mal libro, sino so- bre todo de un libro que muchas personas han disfrutado o de un libro que ha impresionado a los lectores. Además, tenemos que tener en cuenta también el número de ejemplares vendidos que muestra si el libro ha tenido o no éxito. Aun sabiendo que la cantidad no es sinónimo de calidad, pero el valor literario, social, cultural de un libro es muy difícil de evaluar.

\section{B. La lógica de consumo de libros lite- rarios}

Del mismo que las películas o los conciertos, es usual hablar de un libro entre amigos, familiares, compañeros de trabajo. Un estudio de 2007 sobre las actividades que promueven las sociabilización entre las personas, muestra que más está práctica de intercambio de opiniones sobre libros literarios se desarrolla se promueve aún más la sociabilización entre las personas (GIRE ET AL., 2007). En el caso de los bienes culturales, la sociabilización parece especialmente importante. $52 \%$ de personas en Francia lee regularmente y discute de libros, $80 \%$ en el caso de películas y $65 \%$ para el caso de la música. Este estudio muestra que el entorno social juega un papel importante en las prácticas culturales y de ocio. Parece normal entonces, hablar sobre nuestros puntos de vista con los demás. Así lo afirma Christopher Evans, cuando explica que el libro crea relaciones sociales variadas, que van desde "una fluida discusión acerca de una lectura, de un autor, de unaanécdota literaria, etc., a través de la inter-circulación de los libros"; hasta la participación en grupos de lectores, clubes de lectura, tertulias literarias y salones, asociaciones de amigos de tal o cual autor " (BURGOS ET AL, 1996, p.23).

En un artículo publicado en L' Express el 21 de agosto de 2012, Camille Poirier dice que el libro crea vínculos: "Un libro de papel, esto no es sólo una cubertura, unas páginas que se vuelven 
amarillas con el paso del tiempo. Un libro es también un buen material que pasa de mano en mano, abre la discusión y el debate, crea un vínculo social"(POIRIER, 2012 , p.1). Esta señora también se pregunta sobre el futuro de este vínculo, que parece en peligro de desaparecera causa del advenimiento de la tecnología digital. El intercambio y préstamo de libros entre amigos y entre familiares es una de las características históricas delconsumo de libros. Préstamos y donaciones de libros han sido y siguen siendo una práctica común, que va más allá a vecesdel mero ámbito privado. Es cierto que cuando algo nos entusiasta, queremos compartirlo con los demás. El sitio Biglib2 y reúne listos para ofrecer un libro a otros miembros de lectores cada mes que lleva cien libras para cambiar la propiedad. El sitio ofrece Bookcrossing mientras tanto viajar a los libros, el " abandono " en todo el mundo para convertirse en propietario de un nuevo jugador .La blogger Magali Conejero , alias LiliGalipette, en una entrevista nos dijo que a menudo después de leer un libro, lo dejaba en un banca de un parque o en un asiento de un bus, acompañado con una notita que explica lo que aporta la lectura de este libro a la persona que lo lee.4

Normalmente, leemos solos, pero a menudo queremos compartir el placer de la lectura. Un fenómeno acertadamente resumido por el lingüista italiano Raffaele Simone, en un artículo publicado en Courrier International en marzo de 2012: "El libro combina una ambigüedad interesante, el aislamiento más perfecto para una mayor sociabilidad".

Los consumidores de literatura hablan regularmente en su entorno de lo que están leyendo, porque necesitan una opinión positiva que justifique la compra del libro. Por ejemplo, para la temporada literaria 2013 el sector de edición en Francia lanza al mercado, más o menos
646 obras. Entonces ¿Cómo elegir los libros que compramos, dentro de esta amplia selección?

En este contexto, pedir consejo de otros parece esencial, y nuestros amigos, nuestra familia, nuestro entorno puede jugar un papel importante para hacernos comprar algún libro de los que ya han leído. En el artículo "Cosas de consumo: la producción y la experiencia de consumo" (EDGELL ET AL, 1997), los autores muestran la importancia del contexto social y de orientación para los amigos y la familia durante el proceso de consumo. De este modo, desempeñan un papel clave en nuestras decisiones de consumo. Así, se puede decir que en la elección de un libro está también influenciada por el contexto social.

\section{Recomendaciones: receta literaria}

Pero ¿A quién recurrir cuando se necesita un consejo literario? Normalmente, cuando necesitamos ayuda en la compra de un bien, el consumidor va a buscar asesoramiento,es lo que se llama la prescripción, es una opinión particular de una persona sobre un bien. El prescriptor entonces tiene la capacidad de influir en la decisión de compra (BENGHOZI ET AL., 2003). En el caso de un bien como un libro, no es ni el editor ni el autor quienes deben decir que un libro es bueno, sino son los propios consumidores. Hace mucho tiempo ya que Katz y Lazarsfeld (1955) mostraron que los mensajes mediáticos no ejercen ninguna influencia directa en la población. La influencia pasa en primer lugar por los "líderes de opinión" que son personas con más influencia en un grupo (Katz et al, 1955). Según Bernard Cova, especialista en el fenómeno de comunidades de consumidores, el lazo social es, de hecho, más importante que la propiedad en sí, y ejerce en los demás una verdadera influencia en el proceso de consumo (COVA, 1997). 
Armand Hatchuel resume esto en su artículo "Los mercados de prescriptores: crisis del comercio y génesis social". Según este autor, la prescripción se produce cuando el consumidor utiliza una tercera persona para hacer su decisión de compra y se descalifica a sí mismo como el actor principal de su elección (HATCHUEL, 1995).

Para Painbéni (2009), quien llevó a cabo una encuesta entre los profesionales del libro, la prescripción de bienes literarios se caracteriza por tres dimensiones principales: la orientación, el contenido y la fuente de prescripción prevista. Estas dimensiones no siempre son las mismas. Según los profesionales entrevistados en este estudio, la prescripción literaria es una variable que en realidad tiene una influencia en el acto de compra de libros. Painbéni entonces da la siguiente definición: "la prescripción cultural es un conjunto de fuentes de información independiente sobre la calidad de una obra cultural (oferta). Esta información puede ser información cuantitativa o cualitativa, descriptiva o evaluativa (en forma de una opinión positiva o negativa), que sirve para fines comerciales o no comerciales, personales o no personales, y que está a disposición del consumidor " (PAINBÉNI, 2009, p.44).

\section{Los aficionados: aparición y evolu- ción de los nuevos prescriptores}

Un estudio de la evolución del rol de los especialistas muestra que históricamente la opinión y los consejos de estas personas han sido desde siempre mucho más importante que la opinión de los consumidores "lambda" en el proceso de evaluación de una obra literaria. Hasta el siglo XVIII, los intelectuales reconocidos, los llamados "académicos", eran los únicos que podían juzgar el trabajo de los artistas. Este proceso ha sufrido un gran cambio estos últimos años, el acceso masivo de la población a la cultura y a las ar- tes ha democratizado la opinión sobre el valor artístico de una obra (HIRONDELY SONIGO, 2010). Hoy en día, la opinión de la población respecto a una obra literaria o artística es cada vez más tomada en cuenta. El aficionado de literatura ya puede aconsejar; de hecho su opinión tiene el mismo valor que la opinión de los expertos. Así, según los autores de esta tesis, la crítica literaria tiene dos orígenes: por un lado los críticos conocidos y reconocidos como expertos para juzgar la calidad de un producto cultural, y por otro lado los "nuevos expertos", el público, los lectores. En efecto los aficionados de literatura deben también ser considerados como prescriptores en todo el sentido de la palabra.

Pero cabe preguntarse, ¿Cómo la opinión del público pasa de un simple "punto de vista" a una opinión con poder deinfluencia en la actitud de los consumidores? Muchos sociólogos han estudiado el significado de "autoridad" a partir de la cual se ejerce una influencia en el comportamiento del consumidor. Estos estudios nos muestran que existen dos formas de autoridad: la autoridad cognitiva y autoridad informativa. Para Patrick Wilson, la autoridad cognitiva es una relación de influencia de pensamiento en la que participen al menos dos personas, una de las cuales confía en la opinión de la otra, dado que ésta última conoce un área específica de conocimiento (WILSON, 1983). En este caso, la credibilidad y la reputación de la persona que prescribe son esenciales en el proceso de influencia. Broudoux (2007), considera que este tipo de autoridad intelectual es aún más importante cuando se trata de los "aficionados", el consumidor que expresa su opinión sobre todo en la Web. Este tipo de"autoridad"se basa principalmente en la cantidad de la información más que en lacalidad de la opinión. Es importante destacar el rol de los diferentes partes involucradas en la producción de información. La transición a la tecnología digital, 
ha permitidoa todos nosotros transmitir nuestra propia información -un ejemplo concreto es Wikipedia , que utiliza masivamente éste concepto. Lo que ha dado lugar a la llegada de nuevos actores en el sistema de evaluación de una obra literaria, los aficionados.

\section{E. La confianza enotros lectores}

En un estudio sobre el rol de los premios literarios en la decisión de compra, Sylvie Ducas-Spaës (2003) explica que el consumidor de libros literarios confía más en la opinión de otro lector sobre el "valor" del libro que en la opinión de un "erudito". De este modo, el nivel de confianza es más alto entre lectores que entre lector y especialista. Respecto a la "confianza", Bonnarel (2004) distingue tres tipos de "confianza": confianza interpersonal, confianza organizacional, y confianza institucional.

Nuestro análisis se centra más en el proceso y en la relación de confianza interpersonal entre dos personas de diferentes organizaciones. A partir de este tipo de confianza se puede explicar el fenómeno de creer más en lo que dice un "blogger literario" que en lo que dice la publicidad sobre una obra literaria.

La opinión desinteresada de muchas personas tiene más valor que el veredicto elitista de algunos (DUCASSPAËS, 2003). Cabe preguntarse ¿Por qué los consumidores prefieren que un amigo uotro consumidor le densu opinión sobre un libro, en lugar de tomar en cuenta a los profesionales del libro y de la cultura en general (críticos literarios, periodistas)? Según el autor, el mero hecho de que los lectores anónimos no tienen interés en "vender " el libro es suficiente como garantía de imparcialidad y de confianza. Los periodistas son amigos de los autores, que escriben "influenciados" de cierta manera. Los profesionales quieren ganar dinero con la venta de estos libros, por lo que están obligados a hablar bien de un libro. En cambio, el lector anónimo simplemente nos transmite su gusto, lo que le ha gustado o no de un libro. Tiene total libertad en lo que nos dice, su opinión puede ser positiva o negativa, lo que es garantía de libertad de opinión, sin ningún tipo de "influencia". A mayor libertad e independencia mayor es la confianza que se tiene en la opinión de la persona que se expresa (CAVELIER-CROISSANT ET AL., 2004). La crítica "Amateur"sería entonces de alguna manera, una forma de "publicidad independiente y objetiva " (SHRUM, 1996).

Hoy en día, todo hace parecer que los profesionales tradicionales de la edición tienen menos influencia en el lector, este espacio es ocupado por aquellas personas queson más capaces de expresar libremente su opinión (JEANNERET ET $A L, 2005)$. Esta es la razón por la que los "lectores aficionados" pueden convencer mejor al consumidor: ellos conocen bien el "valor" de un libro literario, dominan su "materia" y de este modo informan mejor al lector, lo que permite al consumidor-lector tomar una mejor decisión en medio de una oferta cada vez más numerosa.

Según Larceneux (2007), la opinión "boca en boca" se convertirá cada vez más en la forma de influencia más importante para el éxito de un producto literario, más importante que la publicidad tradicional. Los consumidores están más propensos a comprar un producto del reciben un número importante de recomendaciones positivas que un libro que goce de una gran publicidad. Este estudio, basado en el éxito de taquilla de las películas, muestra que las recomendaciones de los usuarios pueden explicar de manera significativa el éxito de una película. El autor propone en su obra tres formas de interpretar los vínculos entre las recomendaciones y las ventas: 
- Una correlación o simple predicción de ventas: se trata de recomendaciones que anticipan el éxito de un producto. Algunas opiniones de aficionados serían la representación de la opinión de todos los consumidores, y su ausencia no tendría ningún impacto en el éxito de un producto.

- Un "efecto espejo “ predicción de causalidad: las recomendaciones en línea están relacionadas con el nivel de presencia del producto en los medios de comunicación y en la opinión "boca-a-boca". Aquí, la opinión de los críticos en los medios de comunicación tendría un mayor impacto que la opinión de los aficionados.

- Una causalidad directa: las recomendaciones en línea pueden influir en los consumidores, y la ausencia de estas opiniones tendría un impacto negativo en el éxito de un producto.

En cada uno de estos casos, la opinión "boca-de - boca", transmitida a través de Internet, ocupa un lugar muy importante. Para nosotros es interesante probar esta teoría en ese otro producto cultural, como es el libro.

Como se dijo al principio de este artículo, el libro es un bien sujeto a la subjetividad de cada persona: a cada lector le puede gustar o no un libro, de acuerdo con sus propios criterios. Es por eso que es difícil evaluar la calidad de un mismo elemento en diferentes personas. La cantidad de la oferta es otro elemento que hay que tener en cuenta, pues el lector-consumidor se encuentra, en muchos casos, desorientado frente a la inmensa cantidad de libros que se le ofrece. Para ayudarse en una elección difícil el consumidor-lector necesita recurrir al asesoramiento y la ayuda de otras personas. Lo primero que hace es hablar con su círculo familiar o de amigos más próximo, esto es una manera de compartir su opinión. Lo que se busca es facilitar la toma de decisión, a través de la opinión de los prescriptores. En este proceso de decisión, más que los editores o los críticos literarios de costumbre, los aficionados parecen tener cada vez más espacio. Los críticos aficionados, dado que dominan su tema e informan regularmente al lector logran convencer al lector, lo que le permite tomar una decisión frente a una oferta creciente de libros. Este proceso, se ha visto ampliado con la llegada de Internet y la lectura digital.

\section{Capítulo II: El uso de Interneten el mundo de la edición de libros literarios}

\section{A. La presencia de los escritores en la red}

La lectura de libros ha prosperado enormemente en Internet en los últimos años. Por supuesto, el modelo tradicional delaindustria del libro se ha reproducido en la Web: las editoriales tienen su propio sitio web, del mismo modo que los autores y distribuidores, pero la presencia del libro literario en Internet no se limita a ese modelo que es una simple reproducción del modelo tradicional a la Web. Cientos de Blogs literarios, de sitios web, páginas en las redes sociales y otros muestran que el libro está en "todas partes" en internet, mucho más allá del mero patrón habitual de difusión. Los propios autores ahora gestionan su imagen en la Web. Muchos de ellos tienen un sitio web dedicado a sus escritos. A veces sus páginas de Facebook con miles de fans (Stephen King reúne a más de 500.000 aficionados en su sitio web, Frédéric Beigbeder más de 90.000), además de sus cuentas en Twitter permanentemente activas. Un simple captura de pantalla de una página de Twitter como escritor Bret Easton Ellis puede mostrarnos la magnitud de este fenómeno: la gran cantidad de "tweets"del autor muestra la utilización de internet como un medio de comunicar directamente con los lectores, para el deleite de sus 359.349 seguidores: 


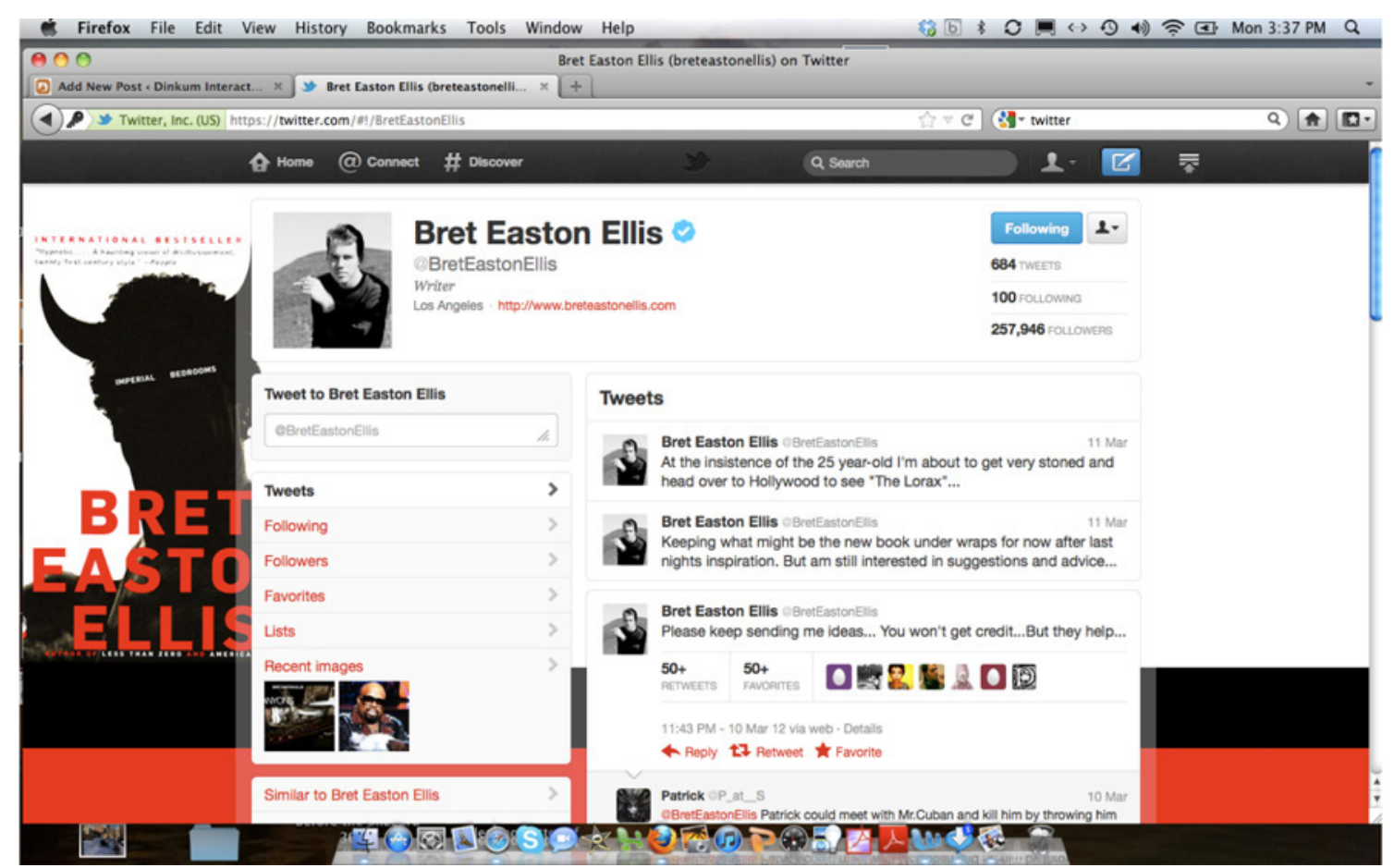

Figura 1: Página Twitter de Bret Easton Ellis, 30 de noviembre de 2012

¿Por qué esa presencia? El autor Harold Cobert, en su sitio Internet "Envied'écrire", explica que su presencia en la web le permite interactuar con sus lectores y bloggers que éstos luego hablen de él. Olivier Steiner va más allá, explicando en una entrevista con la revista literaria marzo 2012 que Facebook es para él como un " puesto de observación". Esta red social le permite encontrar la inspiración: "En tiempos de mucho "falta de inspiración" [... ] hago una pausa y entro en Facebook, miro lo que está sucediendo , lo que se dice; aprovecho para enviar o responder a un mensaje, le deseo feliz cumpleaños a Doe, etc . Y, lo creas o no, siempre hay alguien, una foto, un vídeo, un comentario u otro lo que me hace reiniciar, empujándome hacia adelante, me da un impulso, una nueva aire fresco". François Bon, quien recientemente hizo su alrededor con su polémica traducción de Hemingway dice en su sitio web "Le Tiers libre", que Twitter, a causa de su inmediatez, es un vector de inspiración para la ficción.
Mientras que algunos odian las redes sociales, como Jonathan Franzen (FLOOD, 2012), para otros estas redes son herramientas de comunicación especialmente desarrolladas - y particularmente eficaces. Un ejemplo de esto es el rumor que se ha creado a partir de un "tweet" de Bret Easton Ellis, autor de "American Psycho",diciendo que estaba preparando la continuación de su novela. Enseguida, este autor envio otros "tweets" -desde el 10 de marzo de 2012- que parecían ser las primeras páginas de esta "continuación" de "AmericaPsycho". El rumor se propagó rápidamente por internet y miles de aficionados acudieron en masa para ver estos mensajes, este rumor se propagó por los blogs literarios y las redes sociales, convirtiéndose en una especie de bola de nieve. Un fenómeno como éste, garantiza el éxito comercial de una futura novela.

David Foenkinos, autor del bestseller "La Delicatesse" y nominado para el Premio Goncourt en 2011 por "Les Souve- 
nirs", nos dijo durante una encuentro que además de permitir la promoción de un nuevo libro, las redes sociales son especialmente para él "una práctica": "Al principio, me negué hacer un sitio web de autor; pero ahora me doy cuenta que no hay una forma más sencilla de compartir una noticia de vez en cuando o poner fotos de ediciones de mis libros en el extranjero". Todo este nuevo sistema de comunicación da la oportunidad de compartir fácilmente con los lectores, son útiles para crear conciencia literaria y también sirven para que los autores jóvenes puedan publicar sus novelas. Además, se diferencian de los canales tradicionales como la televisión o la radio, en el sentido de que se dirigen a las personas que ya conocen el autor, "su" público; y ayudan a profundizar más las relaciones entre el autor y su público.

François Bon subraya en su libro "Après le Livre": "los autores de libros y la creación misma cambia con las redes sociales. Hay una etapa en la creación literaria, un espacio de participación para todos" (BON, 2011, p 261).

\section{B. Blogs, redes sociales: la presencia de lectores en la red}

En su estudio de 2008 sobre las prácticas culturales de los franceses, Olivier Donnat (2009) muestra que la escritura digital y auto-expresión se han convertido en prácticas masivas. En promedio, uno de cada cinco internautasfranceses, tiene un blog actualizado regularmente. $62 \%$ de las personas que tienen una actividad de escritura, tiene un sitio web. De este modo los sitios web dedicados a los libros se multiplican cada día más, especialmente los blogs literarios. Pauline Crassard, autor del blog "QuandPaulinelit" recibe un promedio de 75 visitas por día y 2000 páginas vistas por mes. Ella se dio a conocer a través a Twitter, que ya utilizaba antes de abrir su blog; transmite todos los artículos literarios aparecidos en la red social, convirtiéndose así en una especie de relevo entre los autores, editores y los lectores.

Magali Conejero, cuyo blog "Des galipettes entre les lignes" es muy popular en la red, ahora recibe alrededor de 3.000 visitas por meses; dice "Cuando abrí mi blog, yo sabía que tenía una pequeña voz en la blogosfera literaria. Escribí artículos muy cortos, sin mucha investigación $\mathrm{y}$, de hecho irrelevante. Pero yo seguía husmeando en blogs de otras personas y dejando comentarios (a veces mejor escritos que mis propias notas en mi blog). De este modo, gracias a mis seudónimo, los bloggers pudieron seguir el enlace de mi blog y ¡voilá!...mi blog se ha convertido en un éxito". Ahora, el blog de Magali Conejero hace parte de su curriculum vitae, y lo utiliza como una prueba de su experiencia para ser reconocida en el medio literario por sus habilidades de escritura: "Es una vitrina lo suficientemente interesante como para mostrar la capacidad de escritura de contenido web". Una actividad que al comienzo era simplemente una afición se ha convertido en una actividad profesional. Además esta actividad le ha permitido construir una red con otros bloggers, tener nuevas relaciones profesionales a través de Twitter, sitios especializados y redes sociales dedicados al libro como "Babelio". Todos estos sitios que sirven para hablar de los libros, por supuesto, para intercambiar y compartir opiniones y a veces para crear nuevas amistades.

De manera general, hablar de libros en las redes sociales se ha convertido en una manera de darse a conocer en el mundo de las letras. Una persona que constantemente tuitea acerca de los libros actuales es muy probable que los editores y profesionales del libro sigan su cuenta, o se pongan en contacto con ella. Cada día aparecen nuevas páginas en Facebook y nuevas cuentas en Twitter relacionadas con los libros. Los Tumblr, han aparecido 
con mucha fuerza últimamente invadiendo la web literaria. Por ejemplo, "Boloss des belleslettres", un Tumblr muy divertido en el que se resume en un par de frases los clásicos literarios, en un estilo muy familiar utilizando el estilo de los chicos de los barrios y de los suburbios.

\section{Las comunidades de lectores: Ios clubes de lectura modernos}

Junto a los blogs y las redes sociales existen también lo que se llama "comunidades de lectores", que reúnen cientos y miles de personas que expresan libremente su opinión y su comentario sobre una actualidad literaria. Comunidades de lectores como "Babelio", "Livraddict" o "Libfly" y otras se han multiplicado en los últimos años. Estas comunidades encontrar en un solo sitio la síntesis de lo que se existe en las redes sociales y blogs, ya que podemos encontrar comentarios y opiniones, resúmenes, noticias... Es ideal para todo aficionado de lectura literaria.

¿Qué es una "Comunidad de lectores"? El concepto de comunidad en Internet han existido desde hace mucho tiempo, en realidad este concepto aparece al principio de la utilización masiva de Internet. En 1993, Rheingold dio una primera definición: "Las comunidades virtuales son agrupaciones socioculturales que emergen de la red" (RHEINGOLD, 1993). Rauch y Thunqvist en su investigación titulada "Tribus Virtuales: Los consumidores posmodernos en el ciberespacio", demostraron que estas tribus virtuales reunidas en torno a una pasión común han aumentado desde finales de 1990 (RAUCH ET AL., 2000).

Estas comunidades responden a la necesidad del consumidor -que a menudo se encuentra desorientado frente a una oferta masiva-de acudir a los consejos u opiniones de sus compañeros. Gracias a la Internet, la transmisión de los consejos se ve facilitada. Es cierto que anteriormente también se podía conocer a un amigo o a alguien que había leído un libro y a quien se le podía pedir una opinión respecto a ese libro; sin embargo lo que ha cambiado hoy en día es la facilidad para encontrar esa "opinión". Se puede encontrar una revisión directamente en un foro o un blog, o un sitio de ventas como Amazon.

Steyer, García-Bardidia y Quester (2007) han investigado sobre las diferencias entre las llamadas comunidades tradicionales y comunidades en línea, y ponen de relieve una diferencia importante: los encuentros entre los individuos ya no se basan en la proximidad geográfica, sino en cuanto a sus gustos e intereses. Estas comunidades virtuales de consumidores se crean en torno a un producto o tipo de productos, y se utilizan para intercambiar opiniones y consejos directamente.

Las comunidades de lectores trabajan a partir del mismo principio.Es más fácil encontrar en su círculo familiar o de amigos, algunos consejos sobre una determinada marca de gaseosa, que encontrar consejos sobre un producto cultural, sobre un libro literario en particular. Antes de que aparezca Internet, existían ya los clubes o comunidades de lectores. Lo que demuestra que los lugares para intercambiar opiniones o comentarios sobre las lecturas no han aparecido con internet. Lo que ha cambiado es que la organización de este diálogo a través de Internet se ha facilitado: dada la ausencia de limitaciones de tiempo, los usuarios pueden compartir rápida y permanentemente con otros lectores con gustos similares a los suyos. Fejlaoui (2006) pone de relieve el hecho de que muchos consumidores a menudo no encuentran en su entorno una persona experta, capaz de proporcionar la información necesaria para tomar su decisión. Internet ofrece la oportunidad de encontrar e interactuar con otra persona, incluso que no se conoce personalmen- 
te, más fácilmente. Las comunidades de lectores en Internet son, de cierta manera, clubes modernos de lectores. Estas comunidades virtuales proporcionan un espacio virtual dedicado a la lectura social, a partir de los cuales se pueden construir una estrategia para el éxito de un libro. Babelio, por ejemplo es una comunidad de lectores creada en 2007, que cuenta con más de 2 millones de libros en su catálogo, y que reúne cerca de 60,000 miembros, con 830,000 visitantes únicos por mes.

\section{Un lector conectado más activo}

Un lector en busca de información literaria se convertirá fácilmente en internauta, donde todo parece suceder hoy. Así, se puede decir que la literatura ahora vive en parte gracias a la red. Este fenómeno es visible especialmente en medio de los lectores más jóvenes, los de la "Generación Y". Para Chantepie (2009) "Las prácticas artísticas de aficionados, la asistencia a los espacios culturales y el consumo de los medios de comunicación son muy utilizadas entre los más jóvenes, el uso de Internet parece estar relacionada a un interés más amplio en la cultura y la información" (CHANTEPIE, 2009, p.2). Olivier Donnat también declara que el acceso a Internet ha aumentado la demanda de libros literarios. De acuerdo con el gráfico de abajo, en Francia cerca del $60 \%$ de las personas que leen más de 25 libros al año están "conectados" a internet, frente al $40 \%$ de aquellos que no han leído ningún libro.

El Observatorio del libro y de la escritura "Le Motif" en la Ile de France, se ha interesado en lo que representa la Internet en la búsqueda de información literaria "on line" (DAVAL, 2012). Si "Amazon", "Fnac" y "Wikipedia" son los tres primeros resultados que aparecen, otros sitios de información literaria aparecen, tales como "Decitre.fr" (plataforma de venta de libros en línea) 1 que hace parte de los 5 mejores sitios web de referencia. En cuanto a los sitios de "comunidad de lectores", como Babelio se han convertido en sitios "de referencia”. Además de esto, la información publicada en los sitios de terceros, en particular los blogs de lectores, estátambién presente en Internet y constituye el $21 \%$ de los sitios referenciados.

Se nota la importancia de todas estas nuevas formas de comunicación y de intercambio de información en las prácticas de lectura entre los jóvenes. La información se busca ahora utilizando la computadora o el "Smartphone", y los lectores están al tanto rápida y permanentemente de todo lo que pasa en esta Web literaria. De esta manera, se podría llamar a este tipo de lectores conectados como los "prosumers". Este término, introducido por AlvinToffler en su libro The Third Wave (1980), dijo que los nuevos consumidores ya no son pasivos, como antes, sino más bien activos.

Para Kozinets (1999), estos nuevos consumidores conectados son en efecto más activos, participativos, resistentes, activistas, sociales y comunitarios que antes. El autor incluso demuestra el valor superior de "Los consumidores online" en comparación con "Los consumidores offline". Se define además cuatro tipos de pertenencia a una comunidad virtual, dependiendo de la intensidad de la relación social con los demás miembros y la centralidad de la actividad de los consumidores: los "devotees", los "Insiders", los "tourists", y los "minglers".

En este esquema, los "turistas" tienen pocos vínculos sociales con otros miembros de la comunidad y tienen un interés superficial en el consumo. Los "Minglers", a pesar de un interés superficial en la actividad de consumo, mantienen fuertes vínculos con la comunidad. Por el contrario, los "devotos" muestran gran interés por el consumo, pero tienen 
poca conexión con los demás miembros, mientras que los "Insiders" tienen a la vez importantes vínculos con la comunidad, y afinidades con el consumo de la actividad. Estos son, obviamente, el consumidor que tiene mayor importancia en el plan de marketing. Su participación en la comunidad puede fortalecer la lealtad que ya están activamente presentes en el proceso de consumo.

\section{E. Como incentivar la participa- ción de los internautas en la Web literaria}

Es por ello que muchas empresas están buscando federar una verdadera comunidad en torno al producto "libro en línea". Y los ejemplos abundan. Los proyectos de cooperación, invitando al lector a convertirse en un actor cada vez más presente aparecen todos los días. En febrero de 2012, la marca de desodorantes Axe lanzó un cómic interactivo realizado en tiempo real a través de redes sociales, proyecto ideal dirigido al consumidor entre 15 y 25 años (LELONG, 2012). A través Facebook o Twitter, los lectores podían enviar sus ideas sobre la continuación del escenario, y así la historia fue desarrollándose poco a poco de acuerdo a las ideas y a las propuestas de los participantes. Mejor aún, los aficionados podían crear su propio personaje y así ser parte del cómics. Si bien es cierto que, al final, el proyecto no se tradujo en una publicación, ya que la marca no continuo con su impulso, gracias a esta idea de escritura de un texto "on line" y participativo, Axe creo un evento literario en línea lo que le permitió comunicar en torno a su producto.

Otro ejemplo es la operación llevada a cabo por "France Loisirs" y Anna Gavalda, en la que los fans de esta escritora podían escribir una novela participativa a través de una aplicación especial de la página de Facebook; y al mismo tiempo,podían votar por la proposición de los otros lectores) 1. Dicha aplicación fue descargada por más de 3,300 usuarios, que generó 752 aportes, 84 de los cuales fueron finalmente seleccionados para continuar la historia. Siguiendo este esquema, Silvia Hartmann invitó recientemente a los aficionados a leer su manuscrito gradualmente, a través de Google Drive. Su proyecto "Escritor desnudo" o "el autor expone", planea comprometer un poco más a los lectores en la creación de su propio texto (PATEL, 2012). La editorial inglesa Random House ha creado sus propias redes sociales, y Authors Place 2 y Readers Place3 para promover los intercambios directos entre autores y lectores, y ofrece charlas semanales en línea (en Twitter) desde septiembre del 2012 en la que se invita a los lectores a hacer preguntas a los autores.

Las "comunidades de lectores" incitan a sus miembros a participar en estos proyectos de escritura conjunta. En algunos sitios generalistas como Babelio, Book Node4, Goodreads 5, Libfly o Livraddicty Entrée Livre 6, los miembros pueden crear une biblioteca virtual, encontrar informaciones sobre novelas y otros escritos literarios, pero sobretodo pueden intercambiar opiniones e informaciones con otros miembros.

Algunos sitios ofrecen herramientas similares, pero están dedicados a un género en particular. Este es el caso Lecture Academy 1 (libros de fantasía para los jóvenes) o ActuSF2 (Ciencia Ficción). Otros sitios, por último, se centran en el aspecto creativo y ofrecen a los autores aficionados la posibilidad de presentar sus escritos a la comunidad. Por ejemplo, We love words 3 o You Scribe 4. Algunas marcas incluso han creado su propia comunidad de lectores como Orange que ha creado Lecteurs.com. Todas estas comunidades están haciendo esfuerzos para crear una verdadera " tribu" de lectores. De hecho,todas estos sitios literarios animan a sus miembros a considerarse a sí 
mismos como si fueran parte de una "tribu " (OSTERGAARD ET AL., 2000). Otro modo de despertar este sentimiento de "pertenencia a una tribu" es a través de concursos literarios, juegos o retos de escritura que buscan fortalecer la cohesión y el intercambio entre los miembros. El sitio de Goodreads, por ejemplo, ofrece una multitud de juegos en su foro, a veces con premios. Así los miembros de la comunidad se sientenmás implicados, es más algunos miembros están presentes durante todo el día. Los consejos de lectura dados por Goodreads y miembros de la red social, parecen tener un verdadero impacto en los usuarios. Esto demuestra que los lectores "conectados" y participativos parecen más sensibles a la prescripción, y corresponden así a la teoría de la Kozinets (1999).

Podemos ver que el libro se expande a través de Internet, a través de una mayor presencia de lectores y de escritores. Las comunidades de lectores están empezando a tomar una parte cada vez más importante en el mundo literario de la Web, lo que permite a estos diversos actores encontrarsefácilmente en todas estas plataformas de prestación de servicios literarios. De este modo, el lector puede encontrar una gran cantidad de aficionados, cerca de él, a través de Internet, y poder escoger mejor gracias a los consejos que es le ofrecen en la red.

\section{Capítulo III: Comentarios y crítica litera- ria online:¿Lo que influye en el lector?}

\section{A. ¿Un blog o una red social para en- contrar una reseña sobre un libro?}

Como hemos visto, los prescriptores no sólo son los profesionales de la edición sino son ahora principalmente los aficionados y simpatizantes de literatura. La literatura ha conquistado el mundo de la Web, los nuevos fans son los que ha- blan a través de blogs, de redes sociales y de comunidades de lectores. Los líderes tradicionales (periodistas y críticos reconocidos) han perdido su influencia en favor de los se expresan libremente en la red. Según Leroy (2008), la opinión de los individuos en el Internet es sin duda más influente que las comunicaciones oficiales de la propia marca. El famoso jefe de Havas, David Jones explica que en 2008, 20 $\%$ de la gente había cambiado de opinión acerca de un producto o servicio a causa del comentario en un blog o en un foro independiente. En 2010, esta cifra ya se había elevado a 41\% (JONES, 2012). Otro estudio realizado por Jupiter Research Buzz Logic nos dice que los blogs tienen más influencia que las redes sociales en la decisión de compra, son los blogs que ofrecen contenidos variados, a menudo, más elaboradas que los contenidos de las otras redes sociales. Los artículos del blog son a menudo escritos por aficionados, que a menudo le da al blogger, como hemos visto, una verdadera autoridad intelectual. Pierre Assouline, periodista y crítico literario, también explica en una entrevista que "la prescripción literaria tradicional está perdiendo terreno frente a los blogs. Los editores recién se están dando cuenta de este fenómeno y empiezan a reaccionar" (ASSOULINE, 2008, p. 39). La crítica en Internet está cada día más presente y de este modo su influencia es cada vez más importante.

Una encuesta de Livres Hebdo, dirigida específicamente al consumo de libros, revela que los sitios web de interés cultural o blogs en Internet son los que influyen en la decisión de la mayoría de los consumidores. En efecto, estos sitios constituyen el $48 \%$ de las preferencias, muy por delante de las revistas (14\%), de la radio $(13 \%)$ o de la televisión (4\%). Magali La Conejero también confirma esto: "Tengo un pequeño círculo de fieles seguidores que saben pueden encontrar comentarios en mi blog que guían sus 
futuras lecturas"1. Encontramos la misma idea en Pauline Crassard, que explica que algunas personas leen un libro después de leer uno de sus artículos que comenta dicho libro.Y también que algunos bloggers citan un artículo después de leer un postque opina sobre un libro. Cardon y Delaunay - Teterel (2006) examinaron la cuestión de las técnicas relacionales ocultas detrás de los blogs, y así nos dan la clave de cómo algunos bloggers logran encontrar a sus lectores.

Los comentarios recibidos sobre los blogs son de primera importancia, y aumentan los vínculos sociales entre los bloggers: todo el mundo lee y comenta en un blog, con la esperanza de que con el tiempo otras personas vendrán a leer y comentar sobre su propio artículo. Ringoot y Utard (2005) confirman esto, explicando que las interacciones son alentadas por los facilitadores que piden a sus demandan comentarios a los lectores, o que les piden consejos de lectura, por ejemplo.

\section{B. Los profesionales de la edición: en- tre la fascinación y miedo}

Los editores han comprendido que la presencia de libros y autores en Internet ahora es indispensable. Desde 2010, se han multiplicado las alianzas entre las empresas de edición y los blogs. De hecho, los críticos literarios publicados por los bloggers son ampliamente considerados y permiten otra forma de publicidad, más apreciados por los lectores debido a la supuesta honestidad de los críticos aficionados. Pauline Crassarddice que a veces las empresas de edición le envían ejemplares de libros y le piden que haga comentarios sobre la obra en su blog. El mundo de la edición ha incluido estos bloggers directamente en la estrategia de comunicación, enviando libros gratis a través de su servicio de comunicación para beneficiar de la influencia de las críticas de los bloggers. Sin embargo, no todos los bloggers apro- vechan de estos servicios de prensa libre. Por ejemplo Magali Conejero no considera que su blog le da el derecho de pedir libros gratis. "A mi me gusta mi blog, lo que hago es porque me siento feliz y no porque quiero obtener beneficios económicos de una afición (reproducción) sin pagar nada [ ... ] Esto me da la libertad de rechazar en algunas ocasiones propuestas de asociación cuando el libro no me interesa [ ... ]. Yo no compro los libros que cuando los tengo entre las manos no me tientan, entonces ¿Por qué debo leer un libro malo - lo que no me gusta bajo pretexto de que es gratuito"?.

Pero la relación entre los bloggers y editores puede asustar a los periodistas. En la emisión de la radio France Inter "Commeonnous parle" del 09 de agosto de 2012, Mohammed Aïssaoui periodista de la revista Figaro, habla de su miedo a los blogs: "Los lectores pueden ir a los blogs y otros sitios de comentarios en línea y de este modo, pueden dejar de leer los comentarios de los periodistas especializados como yo". Del mismo modo, Aurélie Filipetti, ministro de la cultura en Francia, dijo recientemente en la revista Polka: "Si la prensa abandona la calidad de los comentarios de los periodistas especializados, no habrá ninguna diferencia entre los periódicos, revistas pagadas y la prensa gratuita, especialmente en Internet. Sólo es posible salir de la crisis por la cual los medios de comunicación están pasando, dando más importancia a la calidad, al profesionalismo de un enfoque, de un punto de vista profesional y experto. Es por lo alto que se va a superar la crisis" (GENESTAR, 2012, p.1). Sir Peter Stothard, editor del Times Literary Supplement, dijo en el diario británico The Independent que la crítica tradicional sobre la calidad de un libro literario, está en declive (CLARK, 2012). Según él, el auge de los blogs y sitios web dedicados al libro es un riesgo para la calidad de la literatura. Esto debido a que las opiniones existentes se 
centran demasiado en las afinidades personales, de esta manera algunos libros de baja calidad pueden ser promovidos más de lo que deberían. John Self del periódico The Guardian, refuta esta afirmación citando numerosos blogs literarios de calidad. Según él, estos blogs ofrecen una crítica bien construida, argumentada, y ayudan a llamar la atención sobre otros libros como nuevas publicaciones, contrariamente a las críticas "profesionales" (SELF, 2012).

\section{Herramientas en línea para decidir}

Otro nuevo "espacio" para las críticas literarias, son las "Comunidades de lectores" que sirven también para orientar la elección de los usuarios. Esto lo hacen de forma natural usando las formas clásicas de recomendaciones. Babelio, por ejemplo, tiene un servicio de recomendación ultra- personalizado basado en los libros que los usuarios puedenencontrar en la Biblioteca Virtual.

Los miembros pueden averiguar por qué se recomienda a cada libro, agregarlo a su biblioteca, o especificar porque no están interesados. El miembro también puede obtener sugerencias sobre nuevos temas con la función " seleccionar una categoría (ensayo, drama, historia)". Una innovación importante, que tiende a mejorar con el tiempo. Por su parte, Shelfari un sitio de lectura social, que fue comprado hace unos años por Amazon, utiliza la base de datos de Amazon para encontrar libros y ofrecer al mismo tiempo otras posibilidades de lectura.

GoodReads, uno de los líderes en la comunidad literaria,se ha interesado particularmente en la manera cómo sus miembros descubren nuevos libros. Un estudio realizado por este mismo sitio, a partir de 3,200 usuarios, revela que el $19 \%$ de los miembros descubre nuevos libros desde el primer instante en que se inscriben como miembros del sitio.
De hecho, estos sitios ofrecen en sus páginas de inicio los libros más populares, a menudo best-sellers, que ayudan a establecer el perfil de cada lector según el listado de libros que hace en su biblioteca virtual. Además, el 19\% de los miembros registrados descubren nuevos libros a través del motor de búsqueda, lo que permite poner de relieve una lista enorme de libros. Este resultado confirma la teoría de la "Longuetraîne" de Chris Anderson (2004). Según Anderson, algunas empresas de ventas en línea hacen posible la venta de másproductos en cantidades más pequeñas. Por el mismo principio, muchas pequeñas comunidades de lectores (en cantidad de miembros) permiten descubrir más libros. $13 \%$ de los miembros siguen las recomendaciones personales, como las de Babelio del que hablábamos antes, y el $9 \%$ utiliza la biblioteca de sus amigos para tener una opinión sobre un libro. Así podemos ver que las comunidades pueden ayudar a los lectores a descubrir los libros a través de diversos medios, y de este modo influir en la elección de las lecturas gracias a todos estos útiles.

Dado el éxito de estas comunidades, que permite una visibilidad efectiva de los libros, las empresas de edición buscan crear alianzas y asociaciones con estas comunidades. Gracias a estas formas de colaboración, las empresas de edición pueden crear lazos directos con sus lectores. Por ejemplo, el método de "crítica de la masa" que Babelio ha creado. El principio es simple: Babelio ofrece a los editores presentar los libros a las críticas de los miembros de este club de lectores. El sitio ofrece un libro gratis para los usuarios que deseen publicar un comentario, una reseña o una crítica. Los lectores tienen la oportunidad de descubrir nuevos libros, y sobre todo a compartir su juicio crítico sobre las obras narradas con los otros miembros del sitio. Los editores también se benefician de esto, ellos reciben una recomendación de sus libros como una 
forma de promoción por Internet dirigida a un público especializado. Como este tipo de recomendación funciona gracias a los blogs y la crítica desinteresada de otros lectores, los editores tienen un interés personal en que sus libros sean comentados y criticados por los bloggers. Además, este sistema les permite tener una opinión simple y directade sus publicaciones lo que proporciona una visión general de la evaluación del libro por los usuarios de sitios literarios.

Pero no siempre esta evaluación funciona bien. A veces, como lo dicen Magali Conejero y Pauline Crassard todos los libros recibidos no son necesariamente bien apreciados. En el método de " crítica de la masa", Babelio pide a sus miembros publicar una crítica positiva o negativa. Esto puede ser riesgoso para un libro del que no se esté seguro de su valor literario. Sin embargo, para una editorial, es mejor que se hable de un libro, incluso mal, queno se diga nada en absoluto. Es mejor tener una presencia en Internet, en lugar de correr el riesgo del anonimato completo.

Por otra parte, la influencia de la crítica de aficionados parece aumentar cuando esa crítica se asume con claridad. El estudio "ConsumerAcceptance of Online AgentAdvice: Extremity and PositivityEffects" ha evaluado en efecto la influencia de los comentarios en línea con el grado de positividad: "I love it" (Me encanta) o negativo "I hate it" (lo odio) (GERSHOFF ET AL., 2003). Los autores concluyen que los comentarios sean muy positivos o muy negativos tienen una mayor influencia en el consumo: frente a una opinión muy positiva, porque confiamos en el consejo; frente a una opinión muy negativa porque queremos comprobar por sí mismos. En general, estas comunidades de lectores permiten a los editores hablar de sus libros a través de los bloggers y los internautas, cuya opinión será la teoría más influyente para el consumidor.

\section{Las críticas y las opiniones en la red pueden influir en nuestras decisiones... Pero, ¿cómo?}

Como hemos visto hasta ahora, ser parte de la vida literaria en Internet podría dar lugar a un consumo de libros más fácil. Según Stenger (2008), se observan seis tipos de proceso de decisión de compra en línea. Este tipo de procesos se basan en el papel de la prescripción y en el nivel de habilidad del comprador:

Estos seis tipos de procesos se pueden resumir de la siguiente manera:

1) Satisficing y el azar: el comprador no tiene competencia especial y su decisión no se basa en laopinión de otras personas (prescripción). En este caso el precio juega un papel determinante.

2) Adquisición autónoma: la decisión de compra se basa únicamente en el conocimiento que tiene el comprador.

3) Satisficing asistido: el comprador se basa en la opinión de otras personas (prescripción) porque no tiene competencia específica para orientar su compra.

4) Compra determinada por la opinión de otras personas (prescripción): el prescriptor juega un papel importante en la decisión de compra.

5) Compra consciente y dominada por el comprador: el comprador tiene todos los conocimientos necesarios. Puede combinar estos conocimientos con las opiniones del prescriptor. El comprador es capaz de evaluar por sí mismo las opiniones de los demás.

6) Delegación dela elección: la competencia del comprador es inferior a la del prescriptor, así es éste último que determina la decisión de compra. 
Si Stenger basó su estudio en la compra de vino, el proceso de toma de decisiones en la compra de un libro podría ser sustancialmente equivalente. De este modo, nos enfrentaríamos a una influencia informativa de otros miembros de la comunidad literaria en la web. El lector participa en la comunidad literaria en internet a la búsqueda de este tipo de asesoramiento, que seguirá en mayor o menor grado en función de su propia experiencia.

La Web contribuiría a una nueva forma de prescripción, ya que la llamada autoridad llamada "de información"está permanentemente presenteen la discusión entre pares y en el intercambio de información entre todos los actores del mundo literario. Pero cabe señalar que el riesgo existe, pues todos y cada uno de nosotros puede opinar libremente en internet, entonces no se necesita ser conocido ni experto en un tema para opinar. Lo que pasa es que los internautas tienden a creer como verdad todo lo que se publica en internet. Según Gensollen (2004), tenemos que tener en cuenta que una opinión sobre la calidad de un bien es válida e interpretable, únicamente si se conoce suficientemente a la persona que ha expresado esa crítica.

Esto último, refuerza el interés de los blogs (ya que los blogger se presentan sin tapujos delante de los internautas), y de las comunidades de lectores (ya que cada miembro tiene una página de presentación personal). Esta forma de personalización de la crítica no existe en otros sitios web, que son únicamente informativos. En agosto de 2009, Nielsen llevó a cabo un estudio sobre la búsqueda de información en internet, entre 1800 internautas. Los resultados muestran que $18 \%$ de internautas, utiliza las redes sociales como primer medio donde encontrar información. Esto demuestra que las redes sociales tienen cada vez más importancia y que esta im- portancia se debe a que en Internet hay "demasiada información" y que es muy difícil "perderse" en medio de toda esa cantidad de información.

Pierre Fremaux,co-fundador de Babeliodice: "Usted noescucharía a un extraño que entra en su librería de barrio y que enfáticamente le aconseja leer un libro. En Babelio es lo mismo, usted tiene confianza sobre todo a las críticas de los miembros de su comunidad, lo que deja poco espacio para los extraños" (GARY, 2012). De este modo las críticas y los comentarios de los miembros de blogs, de redes sociales o de comunidades en línea gozan de una mayor credibilidad y una mayor influencia en el lector que busca información.

Hoy por hoy, Internet se ha convertido en nuestra principal fuente de información. El creciente número de estudiantes que copian los artículos de Wikipedia para una presentación oral o un trabajo escolar es una prueba de esto. Pero la pregunta es ¿Cuál es el grado de confianza que se debe tener en lo que lee en Internet? En lo que respecta a la confianza en la web literaria, el riesgo proviene de la " influencia" que el editor o el distribuidor pueden tener a veces en los bloggers. Recibiendo un libro gratuito, el usuario puede sentirse obligado a hablar bien de él, para no ofender al editor y continuar recibiendo libros. Pauline Crassard afirma que a menudo es difícil hacer comentarios negativos, y muchas veces prefiere no publicar ningún artículo, cuando no ha disfrutado de una lectura. La razón es comprensible: el autor podría leer su blog, y ella no quiere hacerle daño.

Otro que se puede observar en la Internet es que todos los bloggers hablen al mismo tiempo de un solo libro, pues todos han recibido el libro el mismo día. Esto, desafortunadamente, puede conducir a un exceso de información en Internet, y el fenómeno de "demasiada infor- 
mación” aparece. Magali Conejero dice: “ Uno de los problemas de los blogs, son los comentarios favorables de los libros recibidos. Es muy molesto leer 17 críticas, favorables y entusiastas, pero aburridas porque todas soniguales sobre un libro enviado por un editor a todos los blogs". Existe otra limitación, las amistades entre los usuarios. Es la famosa obligación "Le cito a usted porque usted me ha citado". De este modo se crean blogósferas al interior del mundo literario en la red, con sus propios líderes, influencias, intercambios de buenas prácticas que pueden poner en riesgo la imparcialidad de la crítica.

El miedo a los falsos críticos también está cada vez más presente. Un estudio de Gartner reveló que en 2014 el $10-15 \%$ de los comentarios en líneaserá falso. Esto no es algo nuevo, pues existen empresas especializadas en crear comentarios positivos sobre un bien o un servicio, con la esperanza de aumentar sus ventas. Rutherford ha creado en 2010 el sitio GettingBookReviews.com que genera muy buenas críticas de libros, como explica en un artículo en el New York Times (STREITFELD, 2012). La tarifa de esta empresa es de US\$ 99 por una reseña del libro, 499 dólares por una opinión positiva de 20 líneas y US\$ 999 por un verdadero elogio del libro de cincuenta líneas. Este caso, que si bien es cierto ha sido denunciado provocando la desaparición de esta empresa, muestra la intensidad de este nuevo "comercio de críticas". Liu Bing, experto en la explotación de datos de la Universidad de Illinois, por su parte, considera que un tercio de los comentarios de los consumidores en la web son falsos, escritos por empresas como el Sr. Rutherford, por los vendedores ellos mismos o por los propios autores bajo seudónimos (STREITFELD, 2012).

En 2012 la BBC de Londres, denunció a Sam Millar por haber publicado bajo identidades falsas, críticas positivas de sus propias obras, y han criticado las obras de su colega Stuart Neville (MCCANN, 2012). Estepráctica llamada sockpuppeting, "marioneta" en español, consiste en crear una nueva cuenta con un nuevo seudónimo para alabar su propio producto. Algunos escritores famosos como RJ Ellory han confesado haber utilizado este método. En una entrevista en la revista ForbesEllory se disculpó diciendo: "Lamento haber tenido poco juicio, lo que me indujo a publicar esos mensajes, yo quiero pedir disculpas a mis lectores y toda la comunidad de autores " (CHARMAN -ANDERSON, 2012, p.1).

Para Pierre Fremaux sin embargo, este fenómeno no tiene mayor importancia: " Existe, por supuesto, editoresque pagan para tener buenas críticas de sus libros en Internet, pero nosotros no pagamos por las críticas falsas [... ] En especial debemos encontrar lectores potencialmente interesados por su crítica, buena o mala. De este modo se construye una estrategia viral, pues esos lectores conquistados hablan del libro a sus amigos. Me paree que las críticas sinceras han socavado el negocio de los vendedores de críticas falsas" (GARY , 2012 , p.1).

De este modo, la prescripciónliteraria en la red parece pasar más por los internautas, a través de redes sociales, blogs y comunidades de lectores. Los editores están desarrollando colaboraciones con estos nuevos prescriptores, que proporcionan una voz y una red particularmente interesante y barata. Pero los profesionales y los propios lectores tienden a desconfiar más entre ellos. Podemos entonces preguntarnos ¿Cuál es el rol exacto que tienen los aficionados de literatura en la prescripción por Internet? y ¿Hasta qué punto los lectores pueden confiar en las críticas de los otros? Es en este contexto específico que se sitúa nuestro estudio cuantitativo. 


\section{Capítulo IV: Análisis de los resultados de la encuesta y recomendaciones}

"Cuando la gente dice que está de acuerdo conmigo, siempre siento que me equivoqué."

\section{Cita atribuida a Oscar Wilde}

El análisis del marco teórico nos ha permitido comprender mejor la prescripción literaria en las redes sociales y los blogs, y el comportamiento del lectorfrente a la crítica literaria en la red. El siguiente paso es estudiar estas teorías y confrontarlas a los consumidores para comprender mejor el impacto de la opinión "boca a boca" y el impacto de la crítica literaria en Internet sobre la decisión de compra. Para esto hemos desarrollado un cuestionario que fue difundido en línea. El objetivo de esta encuesta eraconocer un poco más a los consumidores: ¿Cómo se informan sobre los libros? ¿Cómo eligen los libros? ¿Son más sensibles a la crítica profesional o de los aficionados?

El cuestionario se administró en línea, un modo particularmente oportuno en este estudio para comprender el comportamiento de los usuarios ya que nos "no utilizadores" de internet no forman parte de este estudio. El cuestionario fue desarrollado con la herramienta Google Docs para recoger datos de forma sencilla y rápida.

La recolección de datos se llevó a cabo del 1 a 11 noviembre 2013. Fue transmitido a través de las redes sociales Facebook, Twitter, y Babelio. El cuestionario, fue también difundido por otros bloggers y al mismo tiempo por otros miembros de Babelio que también lo compartieron a través de Twitter o Facebook. Esta difusión en masa dio muchas respuestas muy rápidamente. En dos días, a raíz de un post en la página de Facebook de Babelio, casi 500 personas respondieron al cuestionario.
Al final se generaron 871 encuestas. La participación de todas estas personas se debe también al interés de los encuestados por comprender mejor este fenómeno, ya que muchos de los encuestados dijeron que querían ser informados de los resultados de este estudio.

El análisis de los resultados de la encuesta nos ha llevado a establecer conclusiones interesantes. A partir de estas conclusiones, hemos organizado una serie de recomendaciones que pueden servir a las empresas de edición y a los profesionales del mundo del libro literario.En lo que sigue de nuestro artículo, se hará una presentación de estas recomendaciones.

\section{A. Respecto al proceso de compartir opi- niones entre los aficionados a la lectura}

Antes de la lectura de un libro, la mitad de los encuestados se informa leyendo las críticas de la obra. Esta información se busca principalmente en dos circuitos: internet y el círculo de amigos $y$ de familiares. Muy pocas personas, $4 \%$, se informan sobre un libro a través los canales tradicionales (medios de comunicación, sitios de información cultural, sitios de las empresas de edición, publicidad, etc.).

En principio, a los lectores les gusta opinar y participar en la crítica de un libro. Nueve de cada diez personas encuestadas lo hace regularmente en el seno de su círculo familiar, la mitad lo hace en una red social, y una cuarta parte participa en un blog. Compartir opiniones sobre un libro entre aficionados se ha convertido en una práctica normal, lo que es interesante desde el punto de vista de la comunicación de las empresas de edición.

De hecho, esto es una prueba que confirma que los lectores se informan sobre un libro próximo a ser publicado, y que para eso toman en cuenta más las opinio- 
nes de su círculo cercano. Los consejos de los amigos y de los familiares son de este modo muy importantes para la elección de un libro literario, sobre todo cuando se trata de un autor desconocido. Cerca del $97 \%$ de los encuestados hablan de literatura con sus amigos regularmente, y $50 \%$ lo hace todos los días. Esto confirma que el libro constituye también un elemento de sociabilización, y que este fenómeno se ha intensificado con la Internet.

\section{B. El lector conectado : sobre todo se trata de una lectora y no necesariamen- te de la generación " $Y$ "}

A partir de los resultados de la encuesta es posible ahora personificar un poco más el mundo literario de la Web. Principalmente se trata de un mundo femenino, y no tan joven de lo que se podía esperar. La generación "Y", en la que se incluye a todas las personas entre 18 y 30 años, que en principio parecía que era la más presente en este tipo de consumo, en realidad solo representa $50 \%$ de las personas que participan en una web literaria. La creencia según la cual las redes sociales y los blogs son los dos medios que toda estrategia de comunicación dirigida a jóvenes debe privilegiar, en realidad no se confirma en el sector del libro literario. De este modo, las grandes campañas dirigidas a un público más adulto, pueden realizarse a través las redes sociales y los blogs, y las dirigidas a los jóvenes a través de campañas de publicidad tradicionales.

\section{Publicidad y "éxitos editoriales" : una influencia mínima}

Las campañas de comunicación que se basan sobre los "éxitos editoriales" y una buena publicidad, no tienen mucha influencia en el proceso de decisión de compra de libros literarios. Se debe recordar, sin embargo, que la publicidad es necesaria para hacer conocer un libro, sino se corre el riesgo de "ausencia" en los medios de comunicación, lo que significa que nadie hablara del libro y nadie lo comprará. De hecho, es interesante mostrar que los resultados de nuestra encuesta muestran que son pocos los internautas de la web literaria que toman en cuenta las campañas basadas sobre "éxitos editoriales". Esto se puede explicar por el hecho que esos internautas son personas conocedoras con una buena capacidad de selección, así la Web literaria se diferencia del consumo clásico de libros. De este modo, muchos libros menos conocidos o menos publicitados, pueden gozar de una gran visibilidad en Internet. Los profesionales pueden ponerlos de relieve más fácilmente, a través de operaciones en las comunidades de lectores, o los blogs. Esta es una manera de hacer publicidad interesante y más barata, a la que las empresas de edición, sobre todo las pequeñas y medianas empresas, están dando más importancia cada día.

\section{La prensa escrita y los otros medios de comunicación: necesarios única- mente para la información}

Nuestro estudio confirma que los medios de comunicación tradicionales están perdiendo importancia en el sector de la crítica literaria. Sin embargo, cabe decir que estos medios de comunicación conservan su importancia como útiles de información literaria, quizás a causa de su prestigio y de la imagen de profesionalismo de esos medios. Los grandes lectores normalmente siguen informándose sobre la literatura a través la prensa escrita y hablada; pero también utilizan los sitios de internet especializados en información cultural. Así, lo mejor para una empresa de edición literaria es difundir la información a través los canales tradicionales, pero dando importancia también a los sitios internet especializados. 


\section{E. La presencia en las redes sociales es indispensable, sobre todo para los autores}

La "etiqueta o sello de calidad" dado por una empresa de edición o una colección, no tiene mucha importancia en el momento de la decisión de compra de un libro. Una empresa reconocida mundialmente en el sector de la edición como Gallimard goza de prestigio, incluso si muchos lectores no piensan que esta empresa es realmente sinónimo de calidad. De hecho, la mayoría de lectores no da ninguna importancia al nombre de la empresa de edición.

El nombre del autor, por el contrario, es un "sello de calidad", más que el nombre de la empresa de edición. El nombre del autor influye en $2 / 3$ de las personas que desean comprar un libro. Las páginas web de los autores tienen muchos seguidores, muchos más que los sitios web de las empresas de edición. Para estas empresas, entonces es necesario participar en estas páginas de autores, propiciar una interacción entre los autores y los lectores a través de diálogos directos, darles la posibilidad de hacer preguntas directamente al autor, que el autor tenga la posibilidad de responder a las críticas positivas y negativas, y que comparta estas respuestas con sus "fans". La relación entre el autor y sus lectores es importante para el éxito de las ventas de sus libros hoy en día. Como decía Jean Paul Sartre: "La lectura es un pacto de generosidad entre el autor y el lector, cada uno de los cuales confía en el otro, cada uno de los cuales cuenta con el apoyo del otro".

También hay que resaltar que las críticas en las redes sociales influyen muy poco en el lector. Esto quiere decir que se debe mantener la calma en todas las circunstancias, incluso frente a un tweet o un comentario en Facebook que critican negativamente un libro. Estas críticas no tienen mucho impacto en los lectores.

\section{F. Facilitar el descubrimiento de "nue- vos libros" o "nuevos talentos litera- rios" gracias a Internet}

Nuestro estudio demuestra que el método "tradicional" para atraer la mirada del consumidor de libros sigue siendo el mismo. Los lectores prefieren un libro con una linda portada y con un buen resumen en la contraportada, eso lo saben hacer muy bien las empresas de edición; pero lo que no saben hacer es dar a conocer el libro antes de lanzarloal mercado. Es en este campo que internet tiene un rol importante ya que los editores pueden hacer "descubrir" el libro a través de la red. La combinación de estas dos estrategias garantiza mejor el éxito de ventas del libro. Esta conclusión es muy útil sobre todo para las pymes de la edición, las empresas nuevas en el mercado, o los nuevos autores. El co-fundador de Babelio, Pierre Fremaux, considera que una estrategia que combina la comunicación tradicional y la web literaria, garantiza el éxito de la mayoría de los libros, sea cual sea el género literario.

\section{G. Un lector conectado más participativo en la vida literaria}

Nuestro estudio nos ha permitido ver hasta qué punto el consumo de bienes culturales depende del acceso a Internet. Esto confirma los resultados que Olivier Donnat publicó en 2007 en su estudio sobre las prácticas culturales de los franceses. La web literaria se ha desarrollado mucho, y ciertos sitios como Myboox y Babelio se han convertido en los principales prescriptores literarios hoy en día. Cabe preguntarse ¿Cómo incentivar la participación de los lectores en este nuevo ámbito? Los resultados de nuestro estudio muestran que los concursos literarios y los intercambios con los autores en la Internet son 
dos de los métodos que atraen más a los lectores. La utilización inteligente de estos dos métodos, puede ser utilizada por las empresas de edición no sólo para vender libros sino también para mejorar la imagen de la empresa en el mercado. La mayoría de los lectores desea compartir su opinión sobre un libroen Internet, después de haber "hablado" con el autor o después de haber recibido un libro como regalo.

Brian Klems, en su artículo " 5 Ways Writers Get the Most Out of Goodreads" (2012), habla de la manera cómo, un autor o una editorial, pueden sacar provecho de las comunidades de lectores en Internet. En primer lugar, Klems dice que se debe utilizar las comunidades y grupos de lectores para crear una plataforma literaria en Internet, se debe ofrecer la lectura gratuita de pequeños pasajes del libro en internet, se debe animar a los lectores para que den su opinión o critiquen el libro y que los lectores hagan parte de la discusión con el autor.

Entonces, se necesita animar a los lectores a sentirse parte del proceso de lanzamiento de un libro y parte de la promoción de un autor. La innovación y el humor parecen las dos formas que se tienen que privilegiar para esto. Es lo que la mayoría de los encuestados señala $(74 \%)$. Algunas nuevas empresas de edición, como Charleston, han comprendido muy bien este proceso y saben cómo utilizarlo. Su plan de comunicación a corto plazo se basa principalmente en esta tendencia, utilizando videos en Youtube, imágenes en Tumblr, blogs, e incluso cursos de baile, de charlestón precisamente, y otros eventos sorpresa, antes del lanzamiento de un libro.

\section{H. La transparencia es indispensable en todas las acciones}

De acuerdo a los resultados de nuestra encuesta, los encuestados con- sideran que todo lo que se encuentra en Internet no es necesariamente útil. Por ejemplo, los sitios de comercio electrónico no tienen buena imagen, del mismo modo que las críticas demasiado "buenas" sobre un libro. Quizás esto se deba al fenómeno de "criticas falsas" o sockpuppeting, de las que hablamos antes.

Un resultado inesperado es la confianza de los lectores en los bloggers. Sólo $7 \%$ de los encuestados tiene plena confianza en las críticas literarias de los bloggers. Quizás esto se deba a que la mayoría de los internautas literarios piensa que los bloggers sirven a los intereses de las empresas de edición y que sus críticas no son totalmente objetivas ya que reciben ejemplares de libros gratis y que las empresas de edición promocionan los blog literarios. Los bloggers son considerados como semi-profesionales del mundo de la edición y de este modo han perdido la confianza de sus lectores. De igual manera, en el caso de Facebook y de Twiter, si bien es cierto que estos dos medios tienen poca influencia en el consumidor de literatura (únicamente $3 \%$ de influencia en el momento de la decisión de compra), ni las empresas de edición o los autores, pueden darse el lujo de ignorar el rol de estas redes sociales. El hecho de no responder a una crítica negativa en Facebook o Twitter podría interpretarse como una forma de miedo a las reacciones de los internautas.

Estas son algunas de las conclusiones de nuestra encuesta, que nos han permitido subrayar unos puntos que podrían ser útiles para las empresas de edición.

\section{Conclusión}

Nuestro estudio teórico nos ha permitido de comprender mejor que el consumo de un libro literario está íntimamente ligado a la subjetividad de cada uno de 
nosotros. Del mismo modo, el libro literario participa a la sociabilización de las personas, dado que el lector busca continuamente los consejos de lectura en su círculo familiar y de amigos. Casi siempre estos consejos son dados por otros aficionados de lectura, en los cuales el lector tiene confianza. Se puede decir que el lector de hoy en día se dirige naturalmente a los sitios web literarios, ya sean comunidades de lectores, blogs o redes sociales, en busca de consejos de lectura.

También hemos podido comprobar que el libro literario se ha "liberado", ha salido fuera del círculo restringido de conocedores y expertos, gracias a Internet. Por otro lado, el libro literario se ha convertido en sí mismo como un lugar de encuentro en Internet, para todos los aficionados de lectura. En este aspecto, las comunidades de lectores parecen tener un rol importante, convirtiéndose en una nueva forma de "club de lectura moderno".

De acuerdo con muchos expertos, Internet ha incitado al lector a ser más activo en su pasión, aumentando con esto, el consumo y las posibilidades de compra de libros literarios. Una nueva forma de actividad es la crítica libre y permanente de libros, gracias a la red. La prescripción de libros literarios, se hace cada vez más por Internet. El internauta puede influenciar al lector, y al mismo tiempo, la profesionalización de las relaciones (el caso de los bloggers por ejemplo) y el riesgo de manipulación, pueden limitar esta influencia.

Los resultados de nuestra encuesta, muestran que: intercambiar opiniones y consejos entre aficionados de literatura se ha desarrollado mucho, y continuara desarrollando se aún más, gracias a Internet. Frente a la pérdida de importancia de las formas de comunicación tradicional, como la radio, la televisión, la prensa escrita, la publicidad etc., la decisión de compra de un libro literario se realiza gracias a los blogs y las redes sociales; la presencia de los autores y de las empresas de edición en internet.

\section{Bibliografía:}

\section{Libros}

ANDERSON C. La Longue traîne. 2. ed. Montreuil: Pearson, 2009.

AUSTEN J. (1813), Orgueil et Préjugés, traduction de Pierre Goubert. Paris: Folio, 2007.

BON F. Après le livre. Paris:, Seuil, 2011.

BURGOS M. ; EVANS C.; BUCH E. Sociabilité $d u$ livre et communautés de lecteurs. Bibliothèque publique d'information. Paris: Centre Pompidou, 1996.

COVA B. Au-delà du marché : quand le lien importe plus que le bien. Paris: L'Harmattan, 1997.

EDGELL S.; HETHERINGTON K.; WARDE A. Consumption Matters: The Production and Experience of Consumption. Oxford: Blackwell, 1997.

FOWLER, K.J. Le Club Jane Austen. Paris: Folio, 2007.

GUENASSIA J.M. Le Club des Incorrigibles optimistes. Paris: Albin Michel, 2009.

HATCHUELA. "Les marchés à prescripteurs : crises de l'échange et genèse sociale". In : L'inscription sociale du marché, sous la direction de Jacob Annie et Vérin Hélène. Paris: L'Harmattan, 1995.

JONES D. On a tous à y gagner. Paris: Pearson Editions, 2012.

KATZ E., LAZARSFELD P.F. (1955), Personal influence: The part played by people in the flow of mass communication, Free Press, Glencoe.

KAUFMAN H.; FAGUER L.; GUILLOIS M. Internet a tout changé, rien ne sera plus comme avant. $\mathrm{Pa}$ ris: Kawa Editions, 2009.

LEVAIN M., TISSIER J. La Génération Y par ellemême. Paris: BourinEditeur, 2012.

MANGUEL A. La Bibliothèque, la nuit. Paris: Actes Sud, 2006. 
PENNAC D. Comme un roman. Paris: Gallimard, 1992

RHEINGOLD H. The Virtual Community - Homesteading on the Electronic Frontier. New York: Addison Wesley, 1993.

SARTRE, J. P. Qu'est-ce que la littérature. Paris: Gallimard, 1987.

SOCCAVO L. Gutenberg 2.0, le futur du livre. Paris: M21 Editions, 2008.

TOFFLER A. The Third Wave. Londres: Pan Books, 1980.

WOOLF V. L'Art du roman. Paris: Seuil, 1962.

ZAFON C. L'Ombre du vent. Paris: Le Livre de Poche, 2006.

\section{Informes oficiales y estudios}

BONNAREL F. "La confiance comme mode de contrôle social, l'exemple des cabinets de conseil", thèse de doctorat de Sciences de Gestion, institut de Recherche en gestion, Université de Paris 12 Val de Marne, 2004.

CHANTEPIE P. "Pratiques culturelles chez les jeunes et institutions de transmission : un choc de cultures ?", Culture prospective, N¹, Paris, 2009.

DAVAL M. "E-médiation, le référencement des livres sur Internet”, N² ${ }^{\circ}$, Le MOTif, Paris, 2012.

DE VALCK K. "Le concept des blogueurs : le bouche à oreille dans les communautés en ligne", atelier de recherche appliqué, 8 avril 2009, HEC Paris, 2009.

FEJLAOUI Y. "Leadership d'opinion et communautés virtuelles : un état de l'art", Centre de recherche en gestion, IAE Toulouse I, 2006.

HIRONDEL F., SONIGO S. "Le word-of-mouth marketing appliqué au secteur de l'édition", Mémoire de recherche, HEC Paris, 2010.

JUPITER RESEARCH (2009), "Blog influence on consumer purchase”, étude menée sur 2210 internautes, consultée en ligne sur www.buzzlogic.com, le 14 mai 2012.

LIVRES HEBDO (2012), "Quel type de média vous influence pour vous donner envie de lire un livre?", étude menée sur 1461 internautes, consultée sur http://www.livreshebdo.com, le 2 décembre 2012.
NIELSEN (2009), "Social Media : The nextgreatgateway for content discovery?", étude menée sur un panel de 1800 internautes, consultable en ligne sur le blog http://blog.nielsen.com/, consulté le 13 mai 2012.

ONNAT O. "Pratiques culturelles et usages de l'internet", Ministère de la Culture et de la Communication, coll. "Culture études », DEPS, Paris, 2007.

OSTERGAARD P., JANTZEN C. (2000), "Shifting Perspectives in Consumer Research : From Buyer Behaviour to Consumption Studies". In: BECKMANN S. and ELLIOTT R.H. "Interpretive Consumer Research : Paradigms, Methodologies and Applications", p. 9-23, Copenhagen Business School, 2001.

PAINBENI S. "L'impact de la prescription littéraire dans le processus d'achat d'un roman", Communication présentée aux 14èmes Journées de Recherche en Marketing de Bourgogne (JRMB) Marketing des activités culturelles, du tourisme et des loisirs, Dijon, 2009.

RAUCH D., THUNQVIST G. Virtual Tribes: Postmodern Consumers in Cyberspace, Unpublished Master Thesis, The Market Academy, Stockholm University, 2000.

SHRUM W. "Fringe and Fortune. The role of critics in high and popular art", Princeton University Press, 1996.

WILSON P. Second-hand knowledge. An inquiry into cognitive authority, Greenwood Press. 65, 1983.

\section{Artículos académicos}

BENGHOZI P.-J., PARIS T. "De l'intermédiation à la prescription : le cas de la télévision", Revue française de gestion, Vol. 29, $\mathrm{n}^{\circ} 142$, janvier-février, p. 205-227. 2003.

BROUDOUX E. "Construction de l'autorité informationnelle sur le Web", Documentation Studies, 10 yearsanniversary of Doc. Studies in Tromso, Norway, p. 1-11. 2007.

CAVELIER-CROISSANT V., REBILLARD F., TOUBOUL A. "La promotion de biens culturels par le recours aux genres journalistiques : le cas d'Epok, consumer magazine de la FNAC", Actes du colloque - Les organisations culturelles : une communication spécifique?, Université d'Avignon, p. 35-41. 2004. 
CARDON D. et DELAUNEY-TETEREL H. "La production de soi comme technique relationnelle. Un essai de typologie des blogs par leurs publics", Réseaux $n^{\circ} 138$, p. 15-71. 2006.

DUCAS-SPAES S. "Prix littéraires créés par les médias. Pour une nouvelle voie d'accès à la consécration littéraire?", Réseaux n¹17, p. 47-85. 2003.

GENSOLLEN M. "Biens informationnels et communautés médiatées", Revue d'Economie Politique, Numéro "Marchés en ligne et communautés d'agents", p. 3-40. 2004.

GIRE F., PASQUIER D., GRANJON F. "Culture et sociabilité. Les pratiques de loisirs des Français", Réseaux n¹45-146, p. 159-217. 2007.

GERSHOFF A.D., MUKHERJEE A., and MUKHOPADHYAY A. "Consumer Acceptance of Online Agent Advice: Extremity and PositivityEffects", Journal of Consumer Psychology, N¹3, p. 161170. 2003.

JEANNERET Y., SOUCHIER E. "L'énonciation éditoriale dans les écrits d'écran", Communication et Langages, N¹45, p. 3-15. 2005.

KOZINETS R.V. "E-Tribalized Marketing? The Strategic Implications of Virtual Communities of Consumption“, European Management Journal, Vol. 17, N³, p. 252-264. 1999.

LARCENEUX F. "Buzz et recommandations sur Internet : quels effets sur le box-office ? ", Recherche et Applications en Marketing, Vol. 22, N³, p. 2564. 2007.

LEROY, J. "Gestion de la relation avec une communauté virtuelle dans une stratégie de co-création. Les leçons du cas Fon.com", Décisions Marketing, $\mathrm{N}^{\circ} 52$, p. 41-49. 2008.

RINGOOT R. et UTARD J.M. "Le journalisme en invention : nouvelles pratiques, nouveaux acteurs", Presses Universitaires de Rennes, p.161-202. 2005.

STENGER T. “Le processus de décision d'achat de vin par Internet : entre recherche d'information et prescription en ligne", Décisions Marketing, N49, p.59-70. 2008.

STEYER A., GARCIA-BARDIDIA R. et QUESTER P. "Modélisation de la structure sociale des groups de discussion sur Internet: Implications pour le contrôle du marketing viral", $R e$ - cherche et Applications en Marketing, Vol. 22, $\mathrm{N}^{\circ} 3$, p.29-44. 2007.

\section{Artículos de prensa}

ASSOULINE P. "Y a-t-il un bon usage de Wikipédia ? Entretien", Débat, p. 39. 2008.

CLARK N. "The bionic book worm", The Independent, 25 septembre 2012.

FLOOD A. "Jonathan Franzen : Twitter is the ultimate irresponible medium", The Guardian, 7 mars 2012.

LOUBIERE P. "Comment peut-on éliminer les faux avis de consommateurs sur les sites Internet", Challenges, 29 décembre 2011.

POIRIER C. "Du papier au numérique, quand le livre crée des liens”, L'Express, 21 août 2012.

SELF J. "Why book bloggers are critical to literary criticism", The Guardian, 26 septembre 2012.

SIMONE R. "Les plaisirs singuliers et pluriels de la lecture", Courrier International, 15 mars 2012.

\section{Sitios Internet}

Actu SF, http://www.actusf.com/spip/, última consulta el 1 de diciembre de 2013.

Author's place, http://authorsplace.co.uk/, última consulta el 3 de noviembre 2013.

Babelio, www.babelio.com, última consulta el 1 de diciembre de 2013.

BigLib, http://www.biglib.fr/, última consulta el 2 noviembre de 2013.

BookGlutton, http://www.bookglutton.com/,última consulta el 1 de diciembre de 2013.

Bookcrossing, http://www.bookcrossing.com, última consulta el 20 septiembre de 2013.

BookNode, http://booknode.com, última consulta el 3 noviembre de 2013.

Des galipettes entre les lignes, blog littéraire, www. galipettesentreleslignes.com, consulta el 24 septiembre de 2013.

Entrée Livre, www.entreelivre.com, última consulta el 1 diciembre de 2013. 
Envie d'écrire, "Comment Harold Cobert utiliset-il les réseaux sociaux ?", Entretien vidéo avec Harold Cobert, http://www.enviedecrire.com/comment-les-ecrivains-utilisent-les-reseaux-sociauxharold-cobert/comment-page-1/, consulta el 9 de mayo de 2013.

Facebook, pageauteurdeFrédéricBeigbeder, http:// www.facebook.com/fredericbeigbeder?fref=ts, última consulta el 1 dediciembre de 2012.

Facebook, page auteur de Stephen King, http:// www.facebook.com/stephenkingwriter, última consulta el 1 de diciembre de 2012.

\section{Sitios Internet (2)}

Facebook, page de France Loisirs, "Ecrivez un roman avec Anna Gavalda”, http://www.facebook. com/events/133997769947498/, consulta el 25 de agosto de 2012.

France Inter, "Commeonnous parle", programa del 29 de agosto de 2012, http://www.franceinter.fr/ player/reecouter?play $=440043$, consulta el 30 de agosto de 2012.

Foursquare, https://fr.foursquare.com/, consulta el 1 de diciembre de 2012.

Gartner, “ Gartner Says By 2014, 10-15 Percent of Social Media Reviews to Be Fake, Paid for By Companies", http://www.gartner.com/it/page. jsp?id=2161315, consulta el 19 de septiembre de 2012.

Goodreads, www.goodreads.com, última consulta el 1 de diciembre de 2012.

GoodReads, étude "Anatomy of book discovery? A Case study", http://www.goodreads. com/blog/show/372-anatomy-of-book-discovery-a-case-study, consulta el 23 de septiembre de 2012.

Instagram, http://instagram.com/, última consulta el 1 de diciembre de 2012.

Lecteurs.com, http://www.lecteurs.com/, última consulta el 3 de noviembre de 2012.

LectureAcademy, www.lecture-academy.com, última consulta el 3 de noviembre de 2012.

Les boloss des belleslettres, http://bolossdesbeIleslettres.tumblr.com, consulta el 29 de noviembre de 2013.
Le Tiers Live, www.tierslivre.net, consulta el 2 de abril de 2013.

Les lectures de Lilichat, article sur l'ouvrage "Alice au pays des merveilles", http://over-books.blogspot.fr/2011/12/alice-au-pays-des-merveilles-lewis. html, consulta el 20 de septiembre de 2012.

Libfly, www.libfly.com, última consulta el 3 de noviembre de 2012.

Livraddict, www.livraddict.com, última consulta el 3 de noviembre de 2013.

Myboox, www.myboox.fr, última consulta el 3 de noviembre de 2012.

Quand Pauline Lit, blog littéraire, http://actualitte. com/blog/quandpaulinelit/, consulta el 24 de septiembre de 2013.

Reader's place, http://www.readersplace.co.uk/, última consulta el 3 de noviembre de 2012.

Shelfari, http://www.shelfari.com/, última consulta el 1 de diciembre de 2012.

Twitter, page de Breat Easton Ellis http://twitter. com/BretEastonEllis, consulta el 13 de marzo de 2012.

WeLoveWords, www.welovewords.com, última consulta el 3 de noviembre de 2013.

YouScribe, www.youscribe.com, última consulta el 3 de noviembre de 2012.

\section{Artículos en línea}

BONOD Loys, “J'ai piégé le Net pour donner une bonne leçon à mes élèves”, http://www.rue89. com/2012/03/22/jai-piege-le-net-pour-donner-unelecon-mes-eleves-230452, consulta el 4 de julio de 2013.

CHARMAN-ANDERSON Suw, "Amazon Reviews : R.J. Ellory Apologises for Fakery", http://www.forbes.com/sites/suwcharmananderson/2012/09/03/ amazon-reviews-rj-ellory-apologises-for-fakery/, consulta el10 de marzo de 2013.

GARY Nicolas, "Critiques, commentaires et prescription : une affaire de confiance", http://www. actualitte.com/societe/critiques-commentaires-etprescription-une-affaire-de-confiance-36475.htm, consulta el 5 de septiembre de 2013.

GENESTAR Alain, “J'ai l'amour de la photo”, entre- 
vista con Aurélie Filippetti, http://www.polkamagazine.com/19/le-mur/polka-image/890, consulta el 28 de octubre de 2013.

KLEMS Brian, "5 Ways Writers Can Get The Most Out Of Goodreads", http://www.writersdigest.com/ online-editor/5-ways-writers-can-get-the-most-outof-goodreads, consulta el 5 de septiembre de 2013.

LELONG Benjamin, "Axe Anarchy, la BD participative créée en temps réel par les internautes”, http:// brandsandcontents.com/revue/2012/01/axe-anarchy-la-bd-participative-creee-en-temps-reel-parles-internautes/, consulta el 4 de febrero de 2013.

McCANN Nuala, "NI crime writers Stuart Neville and Sam Millar Crash", http://www.bbc.co.uk/news/ world-europe-19465081, consulta el 5 de septiembre de 2013.

PATEL Murtaza, "Online novel is written in realtime", http://www.springwise.com/entertainment/ online-written-real-time/, consulta el 29 de septiembre de 2013.

STEINER Olivier, "Il faut absolument être moderne", http://www.magazine-litteraire.com/content/ rss/article?id=21785, consulta el 19 de mayo de 2013.

STREITFELD David, "The Best Books Reviews Money Can Buy”, http://www.nytimes.com/2012/08/26/ business/book-reviewers-for-hire-meet-a-demandfor-online-raves.html?pagewanted=1\&_r=2\&, consulta el 26 de Agosto de 2013.

\section{Conferencias}

Conferencia“Je like, tu likes, nous likons", organizadaporLe Motif, Salon del libro de Paris, 17 de marzo de 2012, con Philippe Touron, Pierre Fremaux, David Caviglioli, Sébastien Rouault, y Estelle Divet.

Conferencia “Qu'est-ce que la lecturesociale?", organizada por Le Labo de la edición, Social Media Club, 18 de abril de 2012, con Marc Jahjah, Pierre Fremaux, Sébastien Bago, y Etienne Candel.

Conferencia "Les pratiques des jeunesadultes", organizada por la Sofia, Centro Nacional del libro, 26 de junio de 2012, con Guillaume Teisseire, BarbaraBessat-Lelargey Sonia de Leusse-Le Guillou.

Débat "Quels sont les prescripteurs du livre aujourd'hui ?" Radio France, 25 de noviembrede 2012.

\section{Encuentros y entrevistas}

BAILLY Karine, entrevista del 16 de noviembre de2013

CONEJERO Magalie, bloggeuseLiliGalipette, entrevista del 4 de octubre de 2013

CRASSARD Pauline, bloggeuse QuandPaulineLit, entrevistadel12 noviembrede 2013

FOENKINOS David, entrevista del 3 de octubre de 2013

TEISSEIRE Guillaume, entrevista del 23 de julio de 2013

1 Director de la especialización, Master 2 : "Gestion de empresas culturales e Industrias Culturales", Profesor permanente en "BurgundySchool of Business" (ESC Dijon)

2 Master en gestión Cultural de la ESC Dijon. Asistente de edición y de comunicación en la empresa Ediciones Charleston

3 Extractos de una conferencia pronunciada por Jorge Luis Borges en la Universidad de Belgrano el 24 de mayo de 1978, publicada al año siguiente en el libro Borges oral, Emecé Editores / Editorial de Belgrano, BuenosAires.

4 "It is particularly incumbent on those who never change their opinion, to be secure of judging properly at first." Jane Austen, Orgueil et Préjugés, p. 18, traduit par Pierre Goubert, Folio, 2007. 